Natalia, Sinta Paramita, Septia Winduwati: Aktivitas Komunikasi Social Marketing Organisasi Nirlaba Sebagai Upaya Meningkatkan Kesejahteraan Tuli (Studi Kasus pada GERKATIN Kepemudaan)

\title{
Aktivitas Komunikasi Social Marketing Organisasi Nirlaba Sebagai Upaya Meningkatkan Kesejahteraan Tuli (Studi Kasus pada GERKATIN Kepemudaan)
}

\author{
Natalia, Sinta Paramita, Septia Winduwati \\ natalia.915150106@stu.untar.ac.id,sintap@fikom.untar.ac.id,septiaw@fikom.untar.ac.id \\ Fakultas Ilmu Komunikasi Universitas Tarumanagara
}

\begin{abstract}
GERKATIN Kepemudaan is a non-profit organization that stands to voice equality and equality of Deaf people and becomes a place for Deaf people to be able to work and appreciate themselves widely. The purpose of this study was to determine the activities of social marketing communication carried out by GERKATIN Kepemudaan as an effort to improve Deaf welfare. This study uses the concept of social marketing by Philip Kotler with the application of $7 P$ (Product, Price, Place, Promotion, Personnel, Presentation, and Process). The methodology in this study is a case study with a qualitative approach and descriptive. Data collection techniques are done by in-depth interviews, non-participant observation and online data search. The results of this study are GERKATIN Kepemudaan social marketing carried out in various activities such as campaigns, training, workshops, and festivals with the aim of communicating that Deaf is equal to Listeners as an effort to improve the welfare of Deaf People. Four stages in social marketing management have also been carried out by GERKATIN Kepemudaan and the social marketing implementation carried out by GERKATIN Kepemudaan can be said to have gone well.
\end{abstract}

Keywords: Social Marketing, Deaf Walfare, Nonprofit Organization, GERKATIN Kepemudaan

\begin{abstract}
Abstrak
GERKATIN Kepemudaan merupakan organisasi nirlaba yang berdiri untuk menyuarakan persamaan dan kesetaraan orang Tuli dan menjadi wadah bagi orang Tuli untuk dapat berkarya dan mengapresiasikan diri mereka secara luas. Tujuan penelitian ini adalah untuk mengetahui aktivitas komunikasi social marketing yang dilakukan GERKATIN Kepemudaan sebagai upaya untuk meningkatkan kesejahteraan Tuli. Penelitian ini menggunakan konsep social marketing oleh Philip Kotler dengan penerapan 7P (Product, Price, Place, Promotion, Personnel, Presentation, dan Process). Metodologi dalam penelitian ini adalah studi kasus dengan pendekatan kualitatif dan sifat deskriptif. Teknik pengumpulan data dilakukan dengan wawancara mendalam, observasi non-partisipan dan penelusuran data online. Hasil dari penelitian ini adalah aktivitas social marketing GERKATIN Kepemudaan dilakukan dalam berbagai kegiatan seperti kampanye, pelatihan, workshop, dan festival dengan tujuan mengkomunikasikan bahwa Tuli setara dengan Orang Dengar sebagai upaya untuk meningkatkan kesejahteraan Orang Tuli. Empat tahapan dalam manajemen social marketing pun sudah dilakukan oleh GERKATIN Kepemudaan dan implementasi social marketing yang dilakukan GERKATIN Kepemudaan dapat dikatakan sudah berjalan dengan baik.
\end{abstract}

Kata Kunci: Social Marketing, Kesejahteraan Tuli, Organisasi Nirlaba, GERKATIN Kepemudaan 


\section{Pendahuluan}

Salah satu sistem indera yang berperan penting dalam berkomunikasi adalah pendengaran. Keterbatasan dalam mendengar dapat menghambat seseorang dalam melakukan komunikasi. World Health Organization memperkirakan bahwa pada tahun 2005 terdapat 278 juta orang di dunia mengalami gangguan pendengaran, kurang lebih dua pertiga terjadi di negara berkembang termasuk Indonesia. Pada tahun 2014 angka tersebut melonjak menjadi 360 juta orang atau sekitar lima persen dari populasi di dunia (World Health Organization, 2014 dalam Kardinan, 2014: 2).

Indonesia merupakan salah satu negara dengan jumlah penyandang Tuli terbanyak di Asia Tenggara yang menempati peringkat keempat setelah Sri Lanka, Myanmar dan India, namun hak para tuli seringkali terabaikan. Hal ini terlihat dari pengalokasian terhadap pekerjaan dan akses terhadap pendidikan yang sangat minim. Adanya Undang-Undang Nomor 8 Tahun 2016 tentang Penyandang Disabilitas belum diimplementasikan dengan baik, termasuk terhadap orang tuli. Akses terhadap pendidikan, dan pekerjaan masih minim untuk didapatkan. Contoh paling dasar adalah sistem pendidikan untuk para penyandang disabilitas atau Sekolah Luar Biasa (SLB) khususnya untuk orang tuli belum memfasilitasi pembelajaran bahasa isyarat seperti BISINDO (Bahasa Isyarat Indonesia). Orang tuli lebih banyak diajari metode lisan dengan tujuan orang tuli mampu berbicara dan berkomunikasi seperti orang dengar pada umumnya. Menurut Haenudin (2013: 131), metode lisan merupakan salah satu cara untuk melatih orang tuli agar dapat berkomunikasi secara lisan (verbal) dengan lingkungan orang dengar. Padahal untuk dapat berkomunikasi, orang tuli tidak bisa menggunakan komunikasi verbal.

Hak yang harus diterima orang tuli tidak hanya menjadi tugas pemerintah, tetapi harus ada peran serta dari masyarakat dalam memenuhi hak tersebut. Dengan tujuan untuk terus berjuang menyetarakan kesejahteraan tuli di Indonesia, lahirlah GERKATIN (Gerakan untuk Kesejahteraan Tunarungu Indonesia), sebuah organisasi untuk orang tuli di Indonesia. GERKATIN juga mendirikan GERKATIN Kepemudaan yang dikhususkan untuk Tuli Muda dan anak-anak Tuli. Orang tuli hidup tanpa mendapat akses terhadap suara, terlepas dari itu kehidupan orang tuli selalu berhubungan dengan suara. Orang tuli hanya dapat berkomunikasi dengan komunikasi non verbal menggunakan mimik, gerakan tubuh dan bahasa isyarat. Sangat disayangkan, justru orang dengar tidak peduli dengan hal tersebut, Orang dengar seringkali beranggapan orang tuli tidak dapat diajak untuk melakukan komunikasi karena banyak orang dengar yang tidak dapat memahami cara orang tuli berkomunikasi, padahal tuli bukan hanya sekedar keterbatasan fisik.

GERKATIN Kepemudaan merupakan organisasi yang berdiri untuk menyuarakan persamaan dan kesetaraan orang tuli agar mendapat hak yang sama dengan orang dengar. Organisasi ini menjadi wadah bagi orang tuli untuk dapat berkarya dan mengapresiasikan diri mereka secara luas, oleh karena itu GERKATIN Kepemudaan mengikuti berbagai kegiatan. Tidak hanya menjadi partisipan, GERKATIN Kepemudaan juga menjadi panitia penyelenggara beberapa kegiatan. Kegiatan tersebut bersifat internal maupun eksternal, bertaraf nasional maupun internasional.

Sebagai organisasi nirlaba, GERKATIN Kepemudaan perlu melakukan tindakan nyata tanpa memperhitungkan imbalan yang akan diterima, tindakan tersebut dilakukan untuk dapat merubah pemikiran orang dengar yang menganggap orang tuli terbatas dan tidak bisa melakukan banyak hal. Keterbatasan yang dimiliki 
Natalia, Sinta Paramita, Septia Winduwati: Aktivitas Komunikasi Social Marketing Organisasi Nirlaba Sebagai Upaya Meningkatkan Kesejahteraan Tuli (Studi Kasus pada GERKATIN Kepemudaan)

tidak menghalangi GERKATIN Kepemudaan untuk terus menunjukkan bahwa tuli punya banyak kemampuan selayaknya orang dengar maka tujuan dari penelitian ini adalah untuk mengetahui aktivitas komunikasi social marketing yang dilakukan oleh GERKATIN Kepemudaan dan hasil implementasinya dalam meningkatkan kesejahteraan Tuli.

\section{Metode Penelitian}

Dalam penelitian ini, penulis menggunakan pendekatan deskriptif kualitatif. Ada banyak metode yang dapat digunakan dalam penelitian kualitatif, dalam penelitian ini penulis menggunakan case study research atau studi kasus. Penelitian studi kasus adalah suatu proses pengumpulan data dan informasi secara mendalam, mendetail, intensif, holistik dan sistematis tentang orang, kejadian, latar sosial atau kelompok dengan menggunakan berbagai metode dan teknik serta banyak sumber informasi untuk memahami secara efektif bagaimana orang, kejadian, dan latar sosial berfungsi sesuai dengan konteksnya (Jovita, 2017: 40). Metode pengumpulan data yang dilakukan dalam penelitian ini adalah dengan wawancara mendalam, observasi non-partisipan, studi kepustakaan dan penelusuran data online. Wawancara dilakukan dengan dengan pertanyaan semi terstruktur sehingga dapat memperoleh data yang diperlukan dan sesuai dengan apa yang diteliti.

Dalam penelitian ini, penulis menggunakan dua jenis sumber data yaitu data primer dan data sekunder. Data primer dalam penelitian ini diperoleh dari hasil wawancara penulis dengan informan serta observasi di lapangan yang penulis kumpulkan terkait topik permasalahan yang diteliti, sedangkan data sekunder dalam penelitian ini diperoleh dari buku-buku referensi, makalah, jurnal, skripsi, thesis, dokumen, bahan bacaan, data online serta dokumen pribadi milik lembaga atau organisasi terkait penelitian.

Penelitian ini menggunakan teknik triangulasi metodologis digunakan untuk mempertegas validasi data penelitian yang dilakukan dengan mengumpulkan data sejenis melalui metode pengumpulan data yang berbeda. Triangulasi metodologis merupakan teknik yang tepat untuk menguji keabsahan data dalam penelitian ini, data primer yang penulis dapatkan melalui wawancara mendalam dengan informan akan disesuaikan dengan data yang berasal dari sumber data sekunder sehingga data yang penulis dapatkan menjadi valid.

\section{Hasil Temuan dan Diskusi}

Berdasarkan hasil penelitian yang dilakukan penulis melalui wawancara dengan kelima informan, GERKATIN Kepemudaan dikatakan sebagai organisasi nirlaba karena bergerak dalam bidang pelayanan sosial dan tidak bertujuan untuk mencari laba karena fokusnya adalah pelayanan kepada masyarakat. Philip Kotler dan Gerald Zaltman merupakan pelopor jurnal pemasaran dengan judul Social Marketing: An Approach to Planned Social Change memaparkan bahwa social marketing adalah sebuah desain, implementasi, dan pengendalian program untuk memengaruhi penerimaan ide-ide sosial dan melibatkan pertimbangan dari perencanaan produk, harga, komunikasi, distribusi, dan riset pemasaran (Kotler \& Zaltman, dalam Octahadi 2017: 12). Social marketing merupakan penggunaan prinsip-prinsip dan teknik-teknik pemasaran dalam mempengaruhi target agar secara 
suka rela menerima, menolak, mengubah dan meninggalkan sebuah perilaku demi keuntungan individu, kelompok serta masyarakat sebagai sebuah kesatuan.

Dalam hal ini, GERKATIN Kepemudaan berhasil mempersuasi Teman Tuli untuk secara sukarela menerima identitasnya sebagai Orang Tuli, menolak lupa bahwa mereka memang Tuli, meskipun Tuli mereka tetap bisa mandiri dan tidak perlu dikasihini, Tuli hanya butuh mendapat akses dan fasilitas yang setara, yang sama dengan Orang Dengar, merubah pola perilaku pasif agar menjadi lebih aktif dalam organisasi GERKATIN Kepemudaan sehingga dapat mengulurkan tangan untuk membantu teman-teman Tuli yang lainnya, serta perilaku apatisnya dan berjuang menjadi inspirator bagi Teman Tuli lainnya juga aktivis Tuli untuk terus memperjuangkan hak tuli lewat berbagai kegiatan. Perilaku ini didasarkan pada keinginan anggota GERKATIN Kepemudaan sebagai sebuah kesatuan.

Sesuai dengan apa yang sudah dijelaskan oleh Kotler dan Roberto (dalam Aprinta, Syamsiah dan Hernofika 2017:242), tiga tipe produk sosial GERKATIN Kepemudaan adalah sebagai berikut. Pertama, adanya ide yang lahir untuk menyuarakan kesetaraan hak Tuli dilakukan dengan kreatif lewat berbagai kegiatan. Media yang digunakan adalah website dan berbagai sosial media terutama Instagram, karena Instagram memberikan kontribusi yang besar untuk keberlangsungan promosi kegiatan yang dilakukan GERKATIN Kepemudaan. Lewat kegiatan tersebut, timbul perubahan pengetahuan, sikap dan nilai dalam masyarakat terhadap Orang Tuli. Kedua, praktik sosialnya dilakukan dalam bentuk nyata, berupa ajakan, pembelajaran, demonstrasi, festival, sehingga dapat merubah tingkah laku masyarakat, agar menjadi lebih tertarik dengan kegiatan yang diselenggarakan oleh GERKATIN Kepemudaan, tidak hanya orang tuli tetapi juga orang dengar. Ketiga, produk nyatanya adalah kampanye berbagai kegiatan untuk merubah kebiasaan masyarakat yang menganggap tuli tidak mampu, lewat kampanye tersebut GERKATIN Kepemudaan ingin menyatakan bahwa tuli mampu, kemudian ada penjualan merchandise yang diproduksi sendiri oleh GERKATIN Kepemudaan.

Social marketing yang dilaksanakan oleh GERKATIN Kepemudaan mengacu kepada konsep 7P, namun yang efektif digunakan adalah 4P yaitu (Product, Price, Place dan Promotion) yang akan dijabarkan sebagai berikut. Product dilakukan lewat kegiatan-kegiatan yang bertujuan mengubah persepsi masyarakat tentang Tuli, karena pada hakikatnya tuli sama seperti masyarakat pada umumnya. Tuli dapat mandiri, melakukan segala sesuatunya sendiri, berkarya dan perlu diapresiasi. Oleh karena itu, berbagai kegiatan dilakukan untuk menunjukkan kemampuan Tuli. Price yang harus dikeluarkan terbagi menjadi dua yaitu biaya moneter yaitu biaya yang digunakan untuk keperluan pemasaran dan kegiatan, misal untuk kegiatan perkemahan ada beberapa produk tangible yang harus dibayarkan seperti biaya tempat untuk pelaksanaan kegiatan atau makanan dan minuman untuk konsumsi, sedangkan biaya non-moneter seperti waktu, usaha, energi yang dibutuhkan untuk mengadopsi perilaku tersebut, risiko yang dialami dan perasaan tidak nyaman ketika mengadopsi perilaku yang baru. Misal, ketika ikut kegiatan perkemahan, artinya target adopter harus mulai membuka diri untuk berinteraksi dengan banyak orang namun seringkali perasaan tidak nyaman muncul karena terbiasa untuk menutup diri dan tidak melakukan interaksi dengan orang lain.

Place dilakukan dengan menentukan alur distribusi yang tepat. Alur distribusi yang digunakan adalah the one step flow model dan the two step flow model. Alur distribusi the one step flow model dilakukan dengan menyampaikan pesan langsung kepada sasarannya, misal ketika ada informasi terkait kegiatan atau acara tertentu, 
Natalia, Sinta Paramita, Septia Winduwati: Aktivitas Komunikasi Social Marketing Organisasi Nirlaba Sebagai Upaya Meningkatkan Kesejahteraan Tuli (Studi Kasus pada GERKATIN Kepemudaan)

maka informasi tersebut akan langsung disampaikan tanpa ada perantara. Sedangkan alur distribusi the two step flow model dilakukan melalui media dan bantuan satu perantara sebelum sampai ke sasaran, misal lewat sosial media seperti Instagram kemudian adanya JBI (Juru Bahasa Isyarat) untuk membantu menerjemahkan pesan apa yang ingin disampaikan GERKATIN Kepemudaan kepada masyarakat. Promotion yang dilakukan GERKATIN Kepemudaan lewat berbagai publikasi, sosialisasi dan kampanye baik melalui media maupun kegiatan secara langsung di tempat-tempat tertentu yang diharapkan meningkatkan kesadaran masyarakat untuk lebih terbuka terhadap teman-teman tuli, sehingga teman-teman tuli pun dapat lebih aktif dan menghasilkan karya dengan kemampuan yang dipunya. Harapannya, masyarakat lebih tergerak untuk bersikap sama terhadap orang tuli dan kesejahteraan tuli pun dapat meningkat.

Hambatan yang dihadapi GERKATIN Kepemudaan adalah dalam penerapan 3P (Personnel, Presentation, dan Process). Dalam penyampaian produk sosial terjadi hambatan dalam hal berkomunikasi, karena nyatanya tidak semua orang tuli dapat berkomunikasi dengan baik menggunakan bahasa isyarat. Apalagi orang dengar yang sama sekali tidak paham dengan bahasa tersebut. Miskomunikasi yang terjadi menyebabkan informasi yang disampaikan tidak dapat diterima dengan baik. Sehingga, sebagai social marketer GERKATIN Kepemudaan tidak dapat menyampaikan produk sosial yang ditawarkan secara jelas kepada target adopter secara maksimal, termasuk untuk menjelaskan langkah-langkah yang harus dilakukan agar produk yang ditawarkan dapat diterima. Solusinya adalah pemberdayaan Juru Bahasa Isyarat dan jumlah kuota untuk pembelajaran bahasa isyarat perlu ditingkatkan, agar semakin banyak masyarakat yang mau belajar bahasa isyarat guna mempermudah komunikasi dan penyampaian informasi antara orang tuli dan orang dengar.

Empat tahapan yang dilakukan dalam aktivitas social marketing GERKATIN Kepemudaan seperti yang sudah dijelaskan oleh Kotler dan Roberto (dalam Pudjiastuti, 2016: 33-39) adalah sebagai berikut. Pertama, defining the product market fit, GERKATIN Kepemudaan mendefinisikan produk yang cocok, dalam hal ini berarti GERKATIN Kepemudaan menciptakan produk yang mampu memenuhi keinginan sasarannya. Dalam penelitian ini, keinginan teman-teman tuli dapat terpenuhi lewat akses yang cukup sehingga dapat berkomunikasi dengan bebas. Produk sosial yang ditawarkan misalnya adanya kegiatan temu sapa, sehingga teman tuli dan teman dengar dapat saling bertemu, bersosialisasi, berinteraksi, berbagi pengalaman, belajar dan bermain. Ada juga kampanye kegiatan yang ditawarkan lewat poster untuk mengajak belajar bahasa isyarat.

Kedua, designing the product market fit, GERKATIN Kepemudaan mendesain produk yang cocok untuk dapat diterima oleh masyarakat, dilakukan dengan menerjemahkan sesuatu yang cocok ke dalam pikiran sasaran. Dalam penelitian ini, poster kampanye yang ada dibuat menarik sehingga dapat mempersuasi orang tuli dan orang dengar untuk ikut berpartisipasi. Adanya festival yang memaparkan tentang cara pembuatan film dan video blog sangat bermanfaat bagi teman tuli yang tertarik membuat film dan vlogging, sehingga teman tuli dapat belajar bagaimana cara membuat film dan vlog yang dapat dinikmati tidak hanya oleh orang tuli, tetapi juga oleh orang dengar. Seringkali orang dengar tidak dapat memahami apa yang ingin disampaikan oleh orang tuli.

Ketiga, delivering the product market fit, GERKATIN Kepemudaan mengirimkan produk yang cocok berarti memperhatikan apa yang mau ditampilkan 
kepada target adopter dan apa dibutuhkan dalam pelaksanaan. Misal, kegiatan pembelajaran bahasa isyarat berarti membutuhkan JBI (Juru Bahasa Isyarat) dalam proses pelaksanaannya, dalam hal ini ada adoption triggering sehingga JBI dapat mendemonstrasikan bahasa isyarat untuk dilihat sasaran dan sasaran dapat mempraktikkan langsung penggunaan bahasa isyarat yang digunakan untuk berkomunikasi. Selanjutnya, kegiatan kampanye video blog Tuli berarti membutuhkan vlogger yang sudah ahli sehingga dapat memaparkan praktik pembuatan vlog dan kampanye kreatif, dan target adopter dapat langsung mempraktikkan cara membuat vlog sesuai yang sudah diajarkan. Keempat, defending the product market fit, GERKATIN Kepemudaan mempertahankan produk yang cocok berarti menilai produk yang sudah ada perlu dipertahankan atau diubah sebagai respon terhadap perubahan yang terjadi di masyarakat. Kegiatan kampanye yang dilakukan dalam berbagai bentuk diantaranya lewat poster, ada juga kegiatan festival, workshop atau pelatihan, roadshow film ke beberapa SLB, penjualan merchandise hasil karya teman tuli, dan pengiriman delegasi untuk ikut kegiatan diluar cukup banyak diminati oleh masyarakat baik Orang tuli maupun orang dengar, bahkan kegiatan tersebut dapat melahirkan aktivis tuli, sehingga kegiatan tersebut perlu dipertahankan demi pemberdayaan orang tuli.

Berbagai kegiatan yang dilakukan oleh GERKATIN Kepemudaan adalah upaya untuk mewujudkan kesejahteraan bagi Orang Tuli. Seperti yang sudah dijelaskan oleh Kolle (dalam Rosni, 2017: 57-58), indikator kesejahteraan dapat diukur dari beberapa aspek kehidupan diantaranya adalah (1) dengan melihat kualitas hidup dari segi materi, seperti kualitas rumah dan bahan pangan, (2) dengan melihat kualitas hidup dari segi fisik, seperti kesehatan tubuh dan lingkungan alam, (3) dengan melihat kualitas hidup dari segi mental, seperti fasilitas pendidikan dan lingkungan budaya, dan (4) dengan melihat kualitas hidup dari segi spiritual, seperti moral, etika, dan keserasian penyesuaian. Lewat kegiatan pelatihan atau workshop seperti yang sudah dijelaskan diatas, secara tidak langsung memberikan pendidikan agar orang tuli tidak tertinggal dalam ilmu pengetahuan serta budaya yang terjadi di lingkungan masyarakat, sehingga orang tuli dapat menerima kesejahteraan dalam meningkatkan kualitas hidupnya.

Hasil implementasi social marketing yang dilakukan GERKATIN Kepemudaan dapat dikatakan sudah berjalan dengan baik, terlepas dari hambatan yang sudah dijelaskan sebelumnya. Selain itu, minat dari masyarakat terhadap produk sosial yang ditawarkan meningkat, sebagai contoh masih banyak masyarakat yang awalnya tidak tertarik berpartisipasi dalam kegiatan yang dilaksanakan oleh GERKATIN Kepemudaan padahal kegiatan tersebut membutuhkan volunteer dan tidak banyak masyarakat yang tertarik untuk belajar bahasa isyarat. Peningkatan tersebut dapat dilihat dari animo masyarakat yang tinggi dalam mengikuti kelas bahasa isyarat yang diselenggarakan oleh PUSBISINDO (Pusat Bahasa Isyarat Indonesia), sejam setelah pendaftaran tersebut dibuka kuotanya langsung penuh.

\section{Simpulan}

Kesimpulan dari penelitian yang penulis dapatkan secara keseluruhan, yaitu aktivitas social marketing yang dilakukan oleh GERKATIN Kepemudaan dilakukan dalam berbagai kegiatan misal pelatihan, workshop, dan pembelajaran dengan tujuan mengkomunikasikan bahwa orang tuli setara. Kegiatan tersebut merupakan upaya untuk meningkatkan kesejahteraan orang tuli sehingga orang tuli dapat meningkatkan 
Natalia, Sinta Paramita, Septia Winduwati: Aktivitas Komunikasi Social Marketing Organisasi Nirlaba Sebagai Upaya Meningkatkan Kesejahteraan Tuli (Studi Kasus pada GERKATIN Kepemudaan)

kualitas hidupnya. Empat tahapan dalam manajemen social marketing sudah dilakukan oleh GERKATIN Kepemudaan yaitu dengan mendefinisikan, mendesain, mengirimkan, dan mempertahankan produk sosial yang cocok untuk dapat diterima masyarakat namun penerapan konsep 7P Kotler (Product, Price, Place dan Promotion, Personnel, Presentation, dan Process) Kotler belum dilakukan dengan maksimal karena ada hambatan dalam berkomunikasi. Hasil implementasi social marketing yang dilakukan GERKATIN Kepemudaan dapat dikatakan sudah berjalan dengan baik karena animo masyarakat cukup tinggi untuk mengikuti berbagai kegiatan untuk mendukung orang tuli, contohnya masyarakat mau berpartisipasi untuk ikut kelas pembelajaran bahasa isyarat.

\section{Ucapan Terima Kasih}

Ucapan terima kasih diberikan kepada Fakultas Ilmu Komunikasi Tarumanagara, para narasumber dari GERKATIN Kepemudaan yaitu Siti Rodiah, Isro Ayu Permata Sari, Barrep Saputro, Andi Intan Anjani, dan Dimas Hendrayanto sebagai sumber informasi untuk penelitian ini, serta seluruh pihak yang sudah mendukung dan membantu penulis dalam penelitian ini.

\section{Daftar Pustaka}

Adiningtyas, Adella., Aida Vitayala Hubeis \& Dwi Retno Hapsari. Strategi Hubungan Masyarakat dalam Meningkatkan Citra Organisasi Nirlaba Wolrd Wide Fund For Nature - Indonesia. Jurnal Sains Komunikasi dan Pengembangan Masyarakat [JSKPM], 1 (2), hal. 223-236.

Haenudin. (2013). Pendidikan Anak Berkebutuhan Khusus Tunarungu. Jakarta: Luxima.

Jovita. (2017). Strategi Komunikasi Penggiat Batik Dalam Membangun Kecintaan Masyarakat Terhadap Batik Tradisional. Skripsi, Fakultas Ilmu Komunikasi, Universitas Tarumanagara.

Kardinan, Sammy Samuel Bartimeus. (2014). Karakteristik Pasien Rawat Inap Otitis Media Akut Di Rumah Sakit Immanuel Bandung Periode Januari - Desember 2013. Skripsi, Fakultas Kedokteran, Universitas Kristen Maranatha.

Octahadi, Balqis Kusuma. (2017). Strategi Kampanye Social Marketing Komunitas Earth Hour Jogja Dalam Kampanye 'Switch Off' Dari Tahun 2010-2016. Skripsi, Fakultas Ilmu Sosial dan Ilmu Politik, Universitas Muhammadiyah Yogyakarta.

Pudjiastuti, Wahyuni. (2016). Social Marketing: Strategi Jitu Mengatasi Masalah Sosial di Indonesia. Jakarta: Yayasan Pustaka Obor Indonesia.

Rosni. 2017. Analisis Tingkat Kesejahteraan Masyarakat Nelayan di Desa Dahari Selebar Kecamatan Talawi Kabupaten Batubara. Jurnal Geografi (Online), 9 (1), hal. 53-66. (diakses

dari https://jurnal.unimed.ac.id/2012/index.php/geo/article/viewFile/6038/5367, tanggal 10 November 2018 pukul 16.54 WIB) 